\title{
Correction: Predicting the next Pogačar: a data analytical approach to detect young professional cycling talents
}

\author{
Bram Janssens $^{1}$ (D) Matthias Bogaert ${ }^{1}$ (D) Mathijs Maton ${ }^{1}$
}

(c) The Author(s), under exclusive licence to Springer Science+Business Media, LLC, part of Springer Nature 2022

\section{Correction to: Annals of Operations Research https://doi.org/10.1007/s10479-021-04476-4}

The Spearman scores from the rf_knn and rf_regression models are given an incorrect negative value in Table 6 (upper figure below), while their actual performance should be the opposite value (i.e., 0.5308 , and 0.5779 ).

Original article has been corrected.

Publisher's Note Springer Nature remains neutral with regard to jurisdictional claims in published maps and institutional affiliations.

The original article can be found online at https://doi.org/10.1007/s10479-021-04476-4.

$凶$ Bram Janssens

Bram.Janssens@UGent.Be

Matthias Bogaert

Matthias.Bogaert@UGent.Be

Mathijs Maton

MathijsMaton@hotmail.com

1 Department of Marketing, Innovation and Organisation, Ghent University, Tweekerkenstraat 2, 9000 Ghent, Belgium 